\title{
Citations of Previous Decisions and the Quality of Judicial Reasoning
}

\author{
BY ZSOLT ZŐDI*
}

\begin{abstract}
Inserting citations to authorities into a text, in order to increase the persuasive power of it, and prove the competence of the author, has a long tradition in science and in law. The question is whether this also applies to judicial decisions. This question is especially interesting in a continental legal culture, where following previous cases is not obligatory, there is no stare decisis, and therefore, inserting a reference to a previous case may have a different function. In 2012 we performed a computer-based citation analysis of the court decisions published under FOI act on the official website of the National Office for the Judiciary (Országos Bírósági Hivatal). The article contains four sections. The first and the second sections are dealing with citations within judicial decisions in general, and their significance in different legal cultures. The third section is about the quantitative, while the fourth is about the qualitative part of the research, and tackle the issue whether citations increase the quality of judicial reasoning or not. The answer will be limited to the Hungarian legal culture.
\end{abstract}

Keywords: case law (in Hungary), citations to previous cases, computer based analysis of legal decisions, Hungarian judicial system, judicial reasoning (in Hungary)

\section{INTRODUCTION}

Inserting citations to authorities into a text, in order to increase the persuasive power of it, and prove the competence of the author, has a long tradition in science and in law. Though the quality of a scientific article depends on many factors, one spectacular element is apparently the number of citations. The question is whether this also applies to judicial decisions. This question is especially interesting in a continental legal culture, where following previous cases is not obligatory, there being no stare decisis, and therefore, inserting a reference to a previous case may have a different function. This may be done in order to reflect on the parties' reasoning, to demonstrate the 'long standing judicial practice', or the 'unified application of law', or to increase the persuasiveness of the reasoning towards the higher courts or the general public.

In 2012 we performed a computer-based citation analysis of the court decisions published under FOI act ${ }^{1}$ on the official website of the National Office for the Judiciary (Országos Bírósági Hivatal).The database at that time consisted of a little more than 60,000 Hungarian judicial decisions in electronic format. ${ }^{2}$

1 The Act on Electronic Freedom of Information (Act XC. of 2005. § 16.) introduced the Collection of Judicial Decisions, and publication was started in 2007. Recently the Act on the Organisation and Administration of Courts (Act CLXI. of 2011. § 163.) is regulating the issue.

2 http://www.birosag.hu/ugyfelkapcsolati-portal/anonim-hatarozatok-tara

\footnotetext{
*Research Fellow, Hungarian Academy of Sciences Centre for Social Sciences, Institute for Legal Studies and Senior Lecturer, University of Miskolc, Department of Legal Theory and Legal Sociology. E-mail: Zodi.Zsolt@tk.mta.hu
} 
The method was very simple. A citation in a database ${ }^{3}$ is a hyperlink. A hyperlink always has a starting point in a document and has an end point in another document. Documents have different descriptive data, called metadata, like date (year) of issue, issuing court, issuing chamber (department), subject matter of the decision, judge, parties' counsellors, and so on. The documents at the end of the hyperlink also have these data. With the help of these metadata one could produce statistics from different angles discovering the citation patterns within the corpus.

We have not analyzed all citation types in all documents. Basically we restricted the scope of our research to two fields. The first restriction is that our raw material comprised only the 60,000 non-edited judgments: we excluded the edited judgments from the analysis, and we counted the inserted hyperlinks (starting point of the hyperlinks) only in this pile. The other restriction is that we counted hyperlinks only if they pointed to edited ${ }^{4}$ cases, published by the Supreme Court itself, and in some commercial case reporting journals. With these restrictions we were able to observe the everyday practice of judicial work, and avoided some technical problems. ${ }^{5}$ Finally, apart from the computer based analysis we also conducted manual research on 520 case samples, where we registered additional aspects of citations that otherwise could not have been detected, like style and context of the citation. This part we called the qualitative part.

This article contains four sections. The following second section deals with citations within judicial decisions in general, and their significance in different legal cultures. The third section relates to the quantitative aspects of the research, while the fourth is about the qualitative part of the research, both containing tables and charts, together with interim conclusions. At the end of the fourth section I will briefly tackle the issue indicated in the title of this article: do citations increase the quality of judicial reasoning? The answer will be limited to the Hungarian legal culture.

\section{THE IMPORTANCE OF CITATIONS}

Citations have a long history in- and outside the law. The first law which dealt with the topic was the Lex Citationis (Law of Citations) from the post-classical period of Roman Law. It declared the writings of five roman jurists authoritative: Gaius, Modestinus, Papinian, Paul, and Ulpian, and set up a process if opinions are dissenting. ${ }^{6}$ Whatever the reason for the birth of the law, it clearly shows that references to authorities played an important role in the judicial process, and the emperors wanted to control this.

3 Since the official database is built up from rich text files, it contains no hyperlinks. Therefore we used for the research a commercial legal database (OptiJUS) containing exactly the same items, in a metadated, and hyperlinked format. Special thanks to Opten Ltd., and its CTO Tamás Grósz, for helping me to prepare the queries and the statistics.

4 Editing basically means two operations: adding a headnote and shortening the decision, deleting all the circumstances and texts that have no further relevance to the development of law. (Like technical details of the costs of procedure, dates, and names, etc.)

5 Like the problem of separating the technical citations, citing the case numbers belonging to the case history).

6 A law issued in 426 A.D. by emperor Theodosian and Valentinian. For an analysis of the Lex Citationis see: Watson (2000) 5. For a recent analysis: Austin (2010) 19. 
At the end of the $19^{\text {th }}$ century the number of published cases in the USA increased so rapidly that it caused turbulence in several fields. ${ }^{7}$ Since there was no pre-selection during publishing, (commercial publishers were driven by profit, and increasing output), an enormous number of decisions were printed. The control of the texts (finding and evaluating them), separating the insignificant decisions from important precedents, and "good" law from "bad" became harder and harder. This was the reason for the emergence of the citators. ${ }^{8}$ These books were basically huge tables that showed the references to a particular case, and also described the context of a citation. Context primarily meant positive or negative context, followed or overruled. The best known amongst these citators was the Shepard, which began in 1875 . The Shepard is based on a very simple idea: the more a case is cited in a positive context the more important it is. ${ }^{9}$

When this same increase in quantity became a problem, and as a result a "control crisis" 10 emerged concerning the scientific articles, the method of Shephard was utilized by Eugene Garfield, ${ }^{11}$ a librarian and scientometrist. He created the Science Citation Index, which later became the basis of Impact Factor, a widely used method of measuring the impact of a scientific work. The primary method for measuring the importance of an article, a publication forum (journal), or a scientist is still based on citations. ${ }^{12}$ The third domain where the number of citations and the citing authority has a great significance is search engines. ${ }^{13}$

7 Mr. John West, the founder of the West Publishing Company himself regards this incidence as a turning point in the history of law reports. West (1909-1910) 45.

8 There were, of course, other means of controlling the texts, like new types of indices, the uniform numbering of cases, and the efforts of establishing a centralized law reporter instead of the "multiplicity of reports." West (1909-1910) 7, 5.

9 Bast (1998) 41.

10 The word comes from the seminal book by Beniger (1986).

11 "What is the prospect in scientific literature? The last published edition of the World List of Scientific Periodicals contained more than 50,000 titles in science and technology. It is variously estimated that between 1 and 3 million new scientific articles are published each year." Garfield (1955) 108-111. http://garfield.library.upenn.edu/essays/v6p468y1983.pdf, and later in a video interview told: "People don't even simply know this: there was no citation index at that time for larger rules. It came later. That came out, that Shepard produced that citation index long before we started SCI, because librarians started to complain, that why don't they have a citation index for journals. (...) And I went down to the reference room, and that's when I saw what Shepard Citation was, and I literally screamed, (...) When I saw Shepard, I realized, that the index had to be inverted, because they had the document as the focus, and the statements to be followed." http://www.webofstories. com/play/eugene.garfield/25; jsessionid=1C696C9302267E140AE26CB1273D2833

12 Though since then other methods (like counting the downloads) has emerged, the core of the idea is still the same. A separate journal is devoted to this specific topic, called Scientometrics, (published by Akadémiai Kiadó and SpringerNature) http://link.springer.com/journal/11192

13 The frequency and the context of references, as well as the importance of the citing authorities is a very important (if not the most important) part of the Google-algorithm, PageRank (see: http:// searchengineland.com/what-is-google-pagerank-a-guide-for-searchers-webmasters-11068\#definition). Search engines before Google were all based on free-text search and meta-tags put on webpages. However, it turned out that the data published on the internet is just too much, and cannot be controlled through these two ways. The new method was to use the measurable traces of cognitive authority, generated by human knowledge - in other words, hyperlinks and citations. (for this see: Larry Page: 'PageRank: Bringing Order to the Web', https://web.archive.org/web/20020506051802/www-diglib. stanford.edu/cgi-bin/WP/get/SIDL-WP-1997-0072?1 "The citation graph of the web is an important 
In 1954 John Merryman, a professor in Stanford Law School published an article, where he analyzed the citations in California Supreme Court Decisions. ${ }^{14}$ There he identified several reasons why judges cite authorities. ${ }^{15}$ The most important ones are the following: the idea of predictability and justice (like cases must be decided alike), with the "strong drives toward certainty and simplicity", judges' intention to demonstrate the government of laws, (in contrast to government of men), and finally judges' optimization of workload: the use of accumulated wisdom and experience written in previous decisions helps the judge not to reconsider the problem from its origins, (which is in connection with the phenomena called "inertia", that a judge may frequently find it easier to cite and rely on authority than to think his problem through). Merryman analyzed 298 decisions, with 4917 references, and - at the peak of the legal realist movement - he concluded that the selection of authorities is more a random process than a conscious one.

(...) (T)he judge recognizes that headnotes from previous decisions, no matter how carefully arranged, how accurately copied, how smoothly run together into text, no matter how carefully weighed, distilled and condensed into higher abstractions, do not of themselves decide cases. They are at best data. If the judicial process is to be a conscious, meaningful process the judge must be aware that he selects data, that he formulates questions, that he applies doctrine in his own way, that he achieves results, and that the decisions in earlier cases play only a small part in the total process. ${ }^{16}$

This rather skeptical conclusion is strongly debated by Richard Posner and William Landes ${ }^{17}$ in their article in 1976 . Their starting point is that the body of legal precedents is a "capital stock that yields a flow of information services which depreciates over time as new conditions arise that were not foreseen by the framers of the existing precedents. New (and replacement) capital is created by investment in the production of precedents." For this reason they presuppose that citation is not entirely idiosyncratic, and their article is an attempt to prove this hypothesis by demonstrating certain recurring patterns. The article's conclusions, among others, are that subject matter of the case has a huge significance, that cases decided by upper courts depreciate slower than those of lower courts, and legislative activity depreciates the "precedent-capital" rapidly.

Merryman came back to the topic in 1977 , and further developed the theory of citations with some valuable new thoughts. He compared the judgments of the California Supreme Court from the following three years: 1950, 1960, and 1970. ${ }^{18}$ One of his most important conclusions was that the citation patterns do not change dramatically over time. For example, the average number of citations within the decisions stayed between 16 and17. His other important conclusion is that the citing power of the decisions strongly decreases

resource that has largely gone unused in existing web search engines. We have created maps containing as many as 518 million of these hyperlinks, a significant sample of the total. These maps allow rapid calculation of a web page's "PageRank", an objective measurement of its citation importance that corresponds well with people's subjective idea of importance. Because of this correspondence, PageRank is an excellent way to prioritize the results of web keyword searches. For most popular subjects, a simple text matching search that is restricted to web page titles performs admirably when PageRank prioritizes the results." (Emphasis added - Zs.Z.)
14 Merryman (1953-1954) 613
5 Merryman (1953-1954) 621.
6 Merryman (1953-1954) 673.
7 Landes and Posner (1976) 249.
18 Merryman (1977-1978) 381. 
over time (50-60\% of the citations are to cases decided in the previous decade).${ }^{19}$ This fact partly supports Posner's theory of depreciation.

Finally, a recently published article ${ }^{20}$ dealing with the problem of citations from a different angle states: "Citations function something like the currency of the legal system. An opinion's references to authoritative legal materials, most often the Court's own prior decisions, form the fundamental justification for a judicial decision."21

Citation practice of the common law courts and continental courts strongly differs. ${ }^{22}$ While judicial decisions in common law systems are primary sources of law, and the principle of stare decisis is a fundamental value, in continental legal systems cases are secondary sources (if they are considered as sources of law at all). They only have a subsidiary role in reasoning. Furthermore, there are huge differences between continental legal systems with regards to their attitude towards judge made law, and as a consequence, towards citations. France represents one extreme, because references to previous decisions are practically non-existent, while in Germany the number of decisions containing a citation to a previous decision - in 1992 - was a little bit less than $50 \%$, and the majority of these contain 1-2 citations. ${ }^{23}$ Hungary seems to be somewhere in between: in 2007 the average number of documents containing citations to previous cases was around $30 \%$, but this increased to $40 \%$ in 2012 . Before I try to answer the question posed at the beginning of this paper, I will briefly present the research we have carried out.

\section{RESULTS OF THE COMPUTER BASED RESEARCH}

\section{1. The structure of the Hungarian court system}

The Hungarian court system has four levels. The 111 local courts are the courts of first instance. The second level courts are the county courts, of which there are 20 (one in each of the 19 counties and the Capital Court). There are also four appellate courts. At the top of the judicial system is the Supreme Court called Curia.

Local courts (111 - járásbiróságok, formerly helyi bíróságok) are the courts of first instance. Consequently, they are competent in minor issues. There are separate labor and administrative courts as courts of first instance but there are only 20 of them. They are all located in the county courts' city.

County courts and Capital Court (20 - törvényszékek, formerly megyei bíróságok) decide civil and penal cases having "important" or high value subject matter at the first instance and appellate suits in cases begun at the local level. They are the second instance courts for administrative and labor issues.

The appellate courts' (4 - táblabiróságok) main function is to serve as a second instance court on cases which were decided at the county level. (Normally local courts are

19 Merryman (1977-1978) 396.

20 Cross, Spriggs II, Johnson and Wahlbeck (2010) 489.

21 Over the time a relatively great literature of citation analysis emerged. See e.g.: Johnson (1985) 509; Friedman, Kagan, Cartwright and Wheeler (1981) 773; McCormick (1996) 870; Smith: (2000) 847. For citation analysis in continental legal systems see e.g. Wagner-Döbler and Philipps (1992) 228-242.

22 See e.g. Goutal (1976) 43.

23 Wagner-Döbler and Philipps (1992) 231. 
the courts of first instance, so cases started at county level are special because of their subject matter - e.g. copyright - or because of the value of the lawsuit.)

All county and appellate courts are organized into three departments and further into branches. The main departments are the civil department (subdivided into the normal civil branch, which deals with cases between private parties, and the business branch, which deals with cases between business organizations); the penal department; and - at the County Court - the administrative and labor department (subdivided into an administrative branch, dealing with the supervision of the decisions of the administrative organs, and a labor branch).

The Supreme Court has a double function: it serves as a Court of Cassation in decided cases (as a court of third instance), and has a legal unification role - i.e. its task is to monitor the jurisdiction of lower courts, and in case of divergence to issue certain acts.

\subsection{The data sets}

For the research, we split the data into two parts: to citing and cited documents (precedents). Presently, around 500,000 lawsuits are heard per year in Hungarian courts, and around 11,000 resulting decisions are published. More than $90 \%$ of these latter cases are published under the FOI act, ${ }^{24}$ in their unedited, original form; only the data of the parties are deleted for privacy reasons from the decisions. This database was the one for the research of the citing documents. This database represents the day-to-day practice of the courts in a raw, unedited form. From the beginning of the publication of the decisions in 2007 to the time this research was completed in 2012, the number of items in this database was 61,512 .

Table 1. Unedited judgments (UEJ) in the CJD - Citing documents database

\begin{tabular}{|l|l|l|l|l|l|l|}
\hline & Civil & Business & Labor & Administrative & Penal & Total \\
\hline Supreme Court & 4,873 & 867 & 1,465 & 5,496 & 1,166 & 13,867 \\
\hline Appellate Courts & 9,907 & 3,548 & 0 & 1,172 & 2,704 & 17,331 \\
\hline County Courts & 10,705 & 4,297 & 1,588 & 7,934 & 3,066 & 27,590 \\
\hline Local Courts & 1,396 & 314 & 0 & 0 & 1,014 & 2,724 \\
\hline Total & 26,881 & 9,026 & 3,053 & 14,602 & 7,950 & 61,512 \\
\hline
\end{tabular}

In the abovementioned group, we analyzed the citations of "precedents" that are mainly published in official and private case journals. We went back as early as possible. The different journals were founded at different times. The structure of the cases and the starting date of publication can be found in Table 2 below.

24 The Act on Electronic Freedom of Information (Act XC. of 2005. § 16.) introduced the Collection of Judicial Decisions, and publication was started in 2007. Recently the Act on the Organisation and Administration of Courts (Act CLXI. of 2011. § 163.) is regulating the issue. 
Table 2. Edited decisions, "precedents" - Cited documents

\begin{tabular}{|l|l|l|l|l|}
\hline Type of edited case & $\begin{array}{l}\text { Issuer of } \\
\text { decisions }\end{array}$ & Publisher & $\begin{array}{l}\text { Start date of } \\
\text { collection }\end{array}$ & $\begin{array}{l}\text { Number of } \\
\text { decisions in } \\
\text { total }\end{array}$ \\
\hline Uniformity Decisions (UD) & Supreme Court & Official & $1999(1977)$ & 169 \\
\hline Chamber Opinions (CO) & Supreme Court & Official & 1975 & 1,162 \\
\hline Principal Decisions of the Curia (PD) & Supreme Court & Official & 1999 & 2,441 \\
\hline Court Decisions of the Curia (CD) & Supreme Court & Official & 1975 & 20,118 \\
\hline $\begin{array}{l}\text { Decisions from Collection of Court } \\
\text { Decisions Journal (CCD) }\end{array}$ & $\begin{array}{l}\text { Appellate } \\
\text { Courts }\end{array}$ & Private & 2002 & 2,722 \\
\hline $\begin{array}{l}\text { Decisions from Administrative and } \\
\text { Business Cases Collection (ABC) }\end{array}$ & Supreme Court & Private & 1992 & 5,636 \\
\hline Constitutional Court Decisions (CC) & $\begin{array}{l}\text { Constitutional } \\
\text { Court }\end{array}$ & Official & 1990 & 2,870 \\
\hline Total & & & & 35,118 \\
\hline
\end{tabular}

The main issuer of precedents is the Supreme Court. It regularly publishes four types of documents.

The first is the Uniformity Decision (UD) (before 1997 these had different names, [Elvi döntés]) which decided a controversial legal question that had led to conflicting decisions in lower courts. The UD is formulated like a decision, and - apart from some rare examples - it only decides the debated legal question. This form of decision has a binding power on lower courts.

The second, third and fourth types are non-binding explanatory documents. The second type is the Chamber Opinion (CO) which is a special type of document unknown outside the post-communist world. These are general, abstract rulings of the professional branches within the departments of Curia, which are passed by the body of judges working in the same chamber. Chamber Opinions have great importance in the Hungarian legal system. These quasi-norms do not decide one particular restricted legal problem, but normally they deal with a set of controversial legal questions within a field of law (such as problems of cases regarding joint property or the legal aspects of libel cases). Though these acts have no legal binding power, courts do follow and use them.

Finally, the third and the fourth type contain two sub-types of "precedents". Both are individual cases selected from the jurisprudence of the Supreme Court as a Court of Cassation. The third type is a normal decision, called a court decision (CD), while the other is selected because of its "principal importance" (Principal decision - PD). Both of these are individual decisions, and restricted to one particular legal question.

All of the abovementioned types of documents are published in the official journal of the Supreme Court (Decisions of the Curia - Kúriai Döntések, formerly Bírósági Határozatok, BH).

Private publishers also publish decisions. There are two influential journals: the Collection of Court Decisions (CCD), containing some 400 cases per year, and the Administrative and Business Cases Collection (ABC), with around the same amount.

Besides the abovementioned types, there is one additional "precedent type" which is frequently cited, which is the decisions of the Constitutional Court. The Constitutional Court was established in 1989, and currently publishes about 100 decisions per year. It has 
its own official journal, but the most important decisions are also published in the Official Gazette (Magyar Közlöny).

All of the abovementioned decision types (except constitutional court decisions) have one thing in common: they have an edited headnote, which is typically one or two (in the cases of UD, PD, CD, CCD or ABC) or more (in the case of CO 5-15) amendments. These amendments are formulated like rules of an Act.

\subsection{The results}

3.3.1. The frequency of citations, court levels, branches, document types

The first simple question observed was that of how many of the citing documents (unedited judgments) contain any citations, and references to any edited decisions. We created tables per court level, and per branch.

Table 3a. Citations to edited precedents per branch, figures

\begin{tabular}{|l|r|r|r|r|r|r|r|r|r|}
\hline & $\begin{array}{c}\text { Total } \\
\text { published }\end{array}$ & UD & CO & PD & CD & CCD & ABC & CC & $\begin{array}{c}\text { Total } \\
\text { containing } \\
\text { citation }\end{array}$ \\
\hline Civil branch & 26,881 & 326 & 4,370 & 1,449 & 4,727 & 1,440 & 88 & 1,734 & 9,868 \\
\hline Business branch & 9,026 & 314 & 812 & 728 & 1,565 & 799 & 42 & 75 & 2,685 \\
\hline Labor branch & 3,053 & 50 & 502 & 323 & 1,043 & 12 & 8 & 119 & 1,634 \\
\hline Administrative branch & 14,602 & 267 & 1,928 & 347 & 926 & 19 & 393 & 517 & 3,604 \\
\hline Penal branch & 7,950 & 564 & 600 & 142 & 1,251 & 9 & 4 & 114 & 2,202 \\
\hline All branches total & 61,512 & 1,521 & 8,212 & 2,989 & 9,512 & 2,279 & 535 & 2,559 & $19,993^{*}$ \\
\hline
\end{tabular}

* while figures in UD, CO, etc. columns indicate number of links (references), this column indicates number of documents, and therefore it is not the sum of the preceding columns

Table 3b. Citations to edited precedents per branch, percentages

\begin{tabular}{|l|r|r|r|r|r|r|r|c|}
\hline & UD & CO & PD & CD & CCD & ABC & CC & $\begin{array}{c}\text { Total } \\
\text { containing } \\
\text { citation }\end{array}$ \\
\hline Civil branch & $1 \%$ & $16 \%$ & $5 \%$ & $18 \%$ & $5 \%$ & $0 \%$ & $6 \%$ & $37 \%$ \\
\hline Business branch & $3 \%$ & $9 \%$ & $8 \%$ & $17 \%$ & $9 \%$ & $0 \%$ & $1 \%$ & $30 \%$ \\
\hline Labor branch & $2 \%$ & $16 \%$ & $11 \%$ & $34 \%$ & $0 \%$ & $0 \%$ & $4 \%$ & $54 \%$ \\
\hline Administrative branch & $2 \%$ & $13 \%$ & $2 \%$ & $6 \%$ & $0 \%$ & $3 \%$ & $4 \%$ & $25 \%$ \\
\hline Penal branch & $7 \%$ & $8 \%$ & $2 \%$ & $16 \%$ & $0 \%$ & $0 \%$ & $1 \%$ & $28 \%$ \\
\hline All courts total & $2 \%$ & $13 \%$ & $5 \%$ & $15 \%$ & $4 \%$ & $1 \%$ & $4 \%$ & $33 \% *$ \\
\hline
\end{tabular}

* while figures in UD, CO, etc. columns indicate number of links (references), this column indicates number of documents, and therefore it is not the sum of the preceding columns 
Table 4a. Citations to edited precedents per court, figures

\begin{tabular}{|l|r|r|r|r|r|r|r|r|c|}
\hline & $\begin{array}{c}\text { Total } \\
\text { published }\end{array}$ & UD & CO & PD & CD & CCD & ABC & CC & $\begin{array}{c}\text { Total } \\
\text { containing } \\
\text { citation }\end{array}$ \\
\hline Curia & 13,867 & 361 & 1,052 & 708 & 2,659 & 115 & 190 & 386 & 4,428 \\
\hline Appellate courts & 17,331 & 574 & 2,643 & 1,094 & 3,324 & 1,205 & 90 & 947 & 6,503 \\
\hline County courts & 27,590 & 554 & 4,295 & 1,106 & 3,224 & 900 & 249 & 1,183 & 8,454 \\
\hline Local courts & 2,724 & 32 & 222 & 81 & 305 & 59 & 6 & 43 & 608 \\
\hline & 61,512 & 1,521 & 8,212 & 2,989 & 9,512 & 2,279 & 535 & 2,559 & 19,993 \\
\hline
\end{tabular}

Table 4b. Citations to edited precedents per court, percentages

\begin{tabular}{|l|c|c|c|c|c|c|c|c|c|}
\hline & $\begin{array}{c}\text { Total } \\
\text { published }\end{array}$ & UD & CO & PD & CD & CCD & ABC & CC & $\begin{array}{c}\text { Total ratio } \\
\text { of documents } \\
\text { containing } \\
\text { citations }\end{array}$ \\
\hline Curia & 13,867 & $3 \%$ & $8 \%$ & $5 \%$ & $19 \%$ & $1 \%$ & $1 \%$ & $3 \%$ & $32 \%$ \\
\hline Appellate courts & 17,331 & $3 \%$ & $15 \%$ & $6 \%$ & $19 \%$ & $7 \%$ & $1 \%$ & $5 \%$ & $38 \%$ \\
\hline County courts & 27,590 & $2 \%$ & $16 \%$ & $4 \%$ & $12 \%$ & $3 \%$ & $1 \%$ & $4 \%$ & $31 \%$ \\
\hline Local courts & 2,724 & $1 \%$ & $8 \%$ & $3 \%$ & $11 \%$ & $2 \%$ & $0 \%$ & $2 \%$ & $22 \%$ \\
\hline & 61,512 & $2 \%$ & $13 \%$ & $5 \%$ & $15 \%$ & $4 \%$ & $1 \%$ & $4 \%$ & $33 \%$ \\
\hline
\end{tabular}

3.3.2. Relative popularity of the precedent types

We created one additional simple figure. We wanted to know the "impact factor" of the individual precedent types. For this, we simply divided the number of citations into different precedent types by the total number of all (cited) documents available in databases. (Table 8 represents Table 7 a totals divided by Table 2 totals).

Table 5. Impact of different precedent types

\begin{tabular}{|l|c|c|c|}
\hline & $\begin{array}{c}\text { Number of } \\
\text { decisions in total }\end{array}$ & $\begin{array}{c}\text { Number of } \\
\text { documents citing } \\
\text { the decision type }\end{array}$ & $\begin{array}{c}\text { Impact ratio } \\
\text { (\%) }\end{array}$ \\
\hline Uniformity Decisions (UD) & 169 & 1,521 & 9 \\
\hline Chamber Opinions & 1,162 & 8,212 & 7,1 \\
\hline Principal Decisions of the Curia & 2,441 & 2,989 & 1,2 \\
\hline Court Decisions of the Curia (CD) & 20,118 & 9,512 & 0,5 \\
\hline $\begin{array}{l}\text { Decision from Collection of Court Decisions } \\
\text { Journal (CCD) - Journal of Appellate Courts } \\
\text { (private collection) }\end{array}$ & 2,722 & 2,279 & 0,8 \\
\hline $\begin{array}{l}\text { Decision from Administrative and Business } \\
\text { Cases Collection (ABC) - private collection }\end{array}$ & 5,636 & 535 & 0,1 \\
\hline Constitutional Court Decisions & 2,870 & 2,559 & 0,9 \\
\hline Total & 35,118 & 27,607 & \\
\hline
\end{tabular}


3.3.3. Conclusions from Tables 3-5.

We can see that one-third of the published 61,512 judgments contain a citation to previous cases. But this overall figure varies both by branch and court level.

Regarding the court level, the Curia and county courts are on the average, while appellate courts are above this average and local courts fall below. The higher number of the appellate courts comes from citations to their own decisions published in their own journal (CCD), published by a private publisher. They cite the decisions of the Curia more frequently than lower courts, or than the Curia itself. This surplus is also generated by all branches of the appellate courts. Inserting the documents of the Curia into the decisions often serves as a tool of compliance with the upper courts.

An analysis per branch shows an even greater dispersion of citation frequency. The labor branch tops the list with its $50 \%$ frequency, followed by the other two civil branches. Penal law is the fourth on the list, while administrative law scores lowest. But if we examine the branches together with the court level, the picture is more mixed, because the number of citations fluctuates across the court levels. For example, the number of citations in the penal branch at the Curia is quite high, even higher than in civil law branches, and this surplus is comprised of all precedent types equally. Uniformity decisions, for example, are very popular authorities at the Curia, and cited with significantly more frequency when compared with other branches.

An obvious explanation could be that differences are caused mainly by the civil lawpublic law distinction. Rules are typically dispositive in civil law, and cogent in public law branches, and in penal law the nullum crimen sine lege principle further restricts the available interpretative and argumentative space of the judge. But the Curia's citation activism in the penal field seems to contradict this assumption. Another explanation could be that in penal law, the space for interpretation and the possibility to rely on precedents remains under the monopoly of the Curia, which is reinforcing its own practice.

All tables show the popularity of different precedent types as well. Court Decisions (CD) are the most popular case types referenced. We can find a citation to this type of precedents in $20 \%$ of all cases on average, and more than the half of all citations are CD citations. Here there is a sharp difference: upper courts (Curia, appellate courts) cite around $25 \%$ of CDs, while lower courts (the county and local courts) around $15 \%$ of CDs. But within the lower courts - especially the county courts - this lower percentage is counterbalanced by the more frequent reference to Chamber Opinions. Lower courts use COs more frequently than individual precedent-types.

It further deepens the picture if we look at the relative importance (impact) of the precedent types. Here I used a very simple number: the impact is 1 if one decision is cited in one document. Uniformity decision's impact number of 9 is not surprising: this is the only obligatory instrument. But Chamber Opinion's high impact value (7.1) shows that this a very widely used and popular document type. What is surprising is that privately published CCDs have the same high impact ratio, which is even higher than the CD's impact ratio. The explanation is that courts more willingly cite fresher decisions. The nearly 10,000 CDs majority are overlooked..$^{25}$

25 I have a chart on the age of the cited precedents too. For reference, see: Zödi (2014) 42. http://jog.tk.mta.hu/uploads/files/mtalwp/2014_01_Zodi_Zsolt.pdf 
3.3.4. The change of citations of precedents in time

Table 6. Number of total judgments and citing documents between 2007 and 2012

Values

\begin{tabular}{|c|c|c|c|c|c|c|c|c|c|c|c|c|c|c|}
\hline & \multicolumn{2}{|c|}{2007} & \multicolumn{2}{|c|}{2008} & \multicolumn{2}{|c|}{2009} & \multicolumn{2}{|c|}{2010} & \multicolumn{2}{|c|}{2011} & \multicolumn{2}{|c|}{2012} & \multicolumn{2}{|c|}{ Total } \\
\hline & Total & Citing & Total & Citing & Total & Citing & Total & Citing & Total & Citing & Total & Citing & Total & Citing \\
\hline Curia & 931 & 231 & 2,255 & 576 & 2,547 & 717 & 2,772 & 948 & 2,905 & 981 & 2,457 & 882 & 13,867 & 4,335 \\
\hline Appellate Courts & 1,477 & 452 & 2,918 & 963 & 3,021 & 1,069 & 3,435 & 1,275 & 3,776 & 1,435 & 2,704 & 1,153 & 17,331 & 6,347 \\
\hline Local Courts & 754 & 161 & 666 & 147 & 631 & 151 & 422 & 88 & 223 & 33 & 28 & 4 & 2,724 & 584 \\
\hline Total & 8,117 & 2,210 & 11,487 & 3,299 & 12,230 & 3,759 & 12,438 & 4,335 & 11,073 & 3,944 & 6,167 & 2,438 & 61,512 & 19,985 \\
\hline
\end{tabular}


Table 7. Changes of documents containing citations in percentage per court level

Percentages

\begin{tabular}{|l|c|c|c|c|c|c|c|}
\hline & 2007 & 2008 & 2009 & 2010 & 2011 & 2012 & Total \\
\hline Curia & $25 \%$ & $26 \%$ & $28 \%$ & $34 \%$ & $34 \%$ & $36 \%$ & $31 \%$ \\
\hline Appellate Courts & $31 \%$ & $33 \%$ & $35 \%$ & $37 \%$ & $38 \%$ & $43 \%$ & $37 \%$ \\
\hline County Courts & $28 \%$ & $29 \%$ & $30 \%$ & $35 \%$ & $36 \%$ & $41 \%$ & $32 \%$ \\
\hline Local Courts & $21 \%$ & $22 \%$ & $24 \%$ & $21 \%$ & $15 \%$ & $14 \%$ & $21 \%$ \\
\hline Total & $27 \%$ & $29 \%$ & $31 \%$ & $35 \%$ & $36 \%$ & $40 \%$ & $\mathbf{3 2 \%}$ \\
\hline
\end{tabular}

\section{Chart to Table 7}

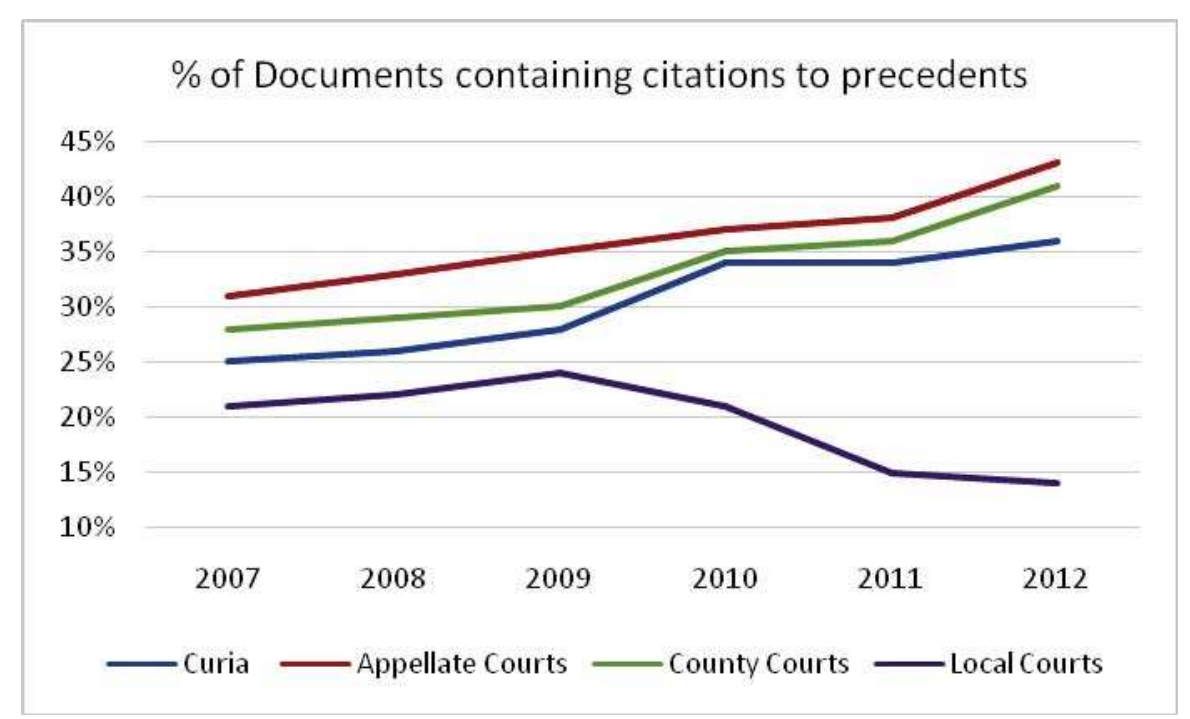

3.3.5. Conclusions to Tables 6-7.

These tables show a clear picture. Apart from local courts ${ }^{26}$, the number of citations used in Hungarian court decisions is increasing over time. The growth is a minimum of $1 \%$ yearly, but in some years $2-4 \%$. The difference between the court levels stays stable. We have no

26 The published judgments of the local courts are not representative, and especially not from years 2011 and 2012. The reason is two-fold: 1 . The publication mechanism of the court website. The main rule is that the final judgments of the Curia and the Appellate Courts should be published, together with the connected first (and in case of supervisory - cassation - decisions of the Curia, second) instance decisions. In case of normal appellate (final) decisions of the appellate courts, the first instance is the county court. Therefore, from this pile there is no local court decision at all from the database. Local court decisions can get into the database if a second instance final county court decision is attacked in a supervisory (cassation) procedure at the Curia, and it is published as a background to its cassation decision, as the first instance decision. 2. Furthermore, as local decisions are the first decisions in time, and the average time of procedure is $1-1,5$ years, a cassation decision of the Curia published in 2012 is typically a finished case that began in 2010 at a local court. This is the reason why there are so few local court decisions from 2011 and 2012. 
data from the previous years, but I assume this was the picture before the start of the database.

This growth has something to do with the change in attitudes of judges and parties towards the precedents, and I assume this is a self-reinforcing process. The availability of decisions, precedents, cases, and especially the increasingly effective search engines and publication methods ${ }^{27}$ are generating more and more citations to precedents. The parties want to win the case, and reasoning with previous cases is one tool for this. If a party cites a precedent, the counterparty should also argue with something, and the judges must somehow reflect on the citations. More published decisions result in more citations, and the habit of frequent citation involves a greater need for publishing more cases.

3.3.6. The impact of fields of law, and sub-fields of law to citations of precedents

One of our hypotheses was that the field of law (case type) strongly influences the precedent intensity and that there is a great difference between case types. The following table presents the number of citations to precedents per field of law (case type) in one branch, as an illustration..$^{28}$ (The results of other branches are not significantly different from this.) We prepared statistics only for the most frequent case types. Within one row, on the left side, there are 7 entries, namely the total number of judgments within the database (column 2) and the number of precedent-citing documents within the field (column 3) followed by the number of citing documents per precedent type (columns 4-8). The right part of the table shows some ratios, like the percentage of citing documents within the whole (column 9 column 3 divided by column 2) and the percentage of the citing documents per precedent type within citing documents (columns 10-14 - columns 4-8 divided by column 3 ). All of the 5 tables are sorted by the ratio of citing documents (column 9).

27 In the most widely used legal databases the important case-types (in some, all case types except (C), can be inserted into the text of the law, visually offering a connected case.

${ }^{28}$ We prepared these tables for all departments and branches, but, because the overall picture is very much the same there, I do not insert these tables. For these see the Hungarian working paper of this research, Zödi (2014) 33-38. 
Table 8. Number of precedent types and ratios per case type at the civil department

\begin{tabular}{|c|c|c|c|c|c|c|c|c|c|c|c|c|c|}
\hline & $\begin{array}{c}\text { Total } \\
\text { judgments }\end{array}$ & \begin{tabular}{|c} 
Judgments \\
with citations \\
to precedents
\end{tabular} & UD & $\mathrm{CO}$ & $\mathrm{PD}$ & $\mathrm{CD}$ & $\mathrm{CC}$ & \begin{tabular}{|c|} 
Ratio of \\
citing \\
documents
\end{tabular} & $\begin{array}{l}\text { Ratio of } \\
\text { UD }\end{array}$ & $\begin{array}{c}\text { Ratio of } \\
\text { CO }\end{array}$ & $\begin{array}{c}\text { Ratio of } \\
\text { PD }\end{array}$ & $\begin{array}{c}\text { Ratio of } \\
\text { CD }\end{array}$ & $\begin{array}{c}\text { Ratio of } \\
\text { CC }\end{array}$ \\
\hline $\begin{array}{l}\text { Termination of } \\
\text { joint property }\end{array}$ & 583 & 320 & 5 & 611 & 13 & 173 & 1 & $55 \%$ & $2 \%$ & $191 \%$ & $4 \%$ & $54 \%$ & $0 \%$ \\
\hline $\begin{array}{l}\text { Infringement of } \\
\text { personal rights }\end{array}$ & 2,588 & 1,377 & 10 & 1,310 & 289 & 1,051 & 1,686 & $53 \%$ & $1 \%$ & $95 \%$ & $21 \%$ & $76 \%$ & $122 \%$ \\
\hline $\begin{array}{l}\text { Determination of } \\
\text { ownership }\end{array}$ & 1,004 & 426 & 125 & 310 & 71 & 466 & 60 & $42 \%$ & $29 \%$ & $73 \%$ & $17 \%$ & $109 \%$ & $14 \%$ \\
\hline $\begin{array}{l}\text { Payment of } \\
\text { contractual price }\end{array}$ & 370 & 145 & 8 & 42 & 23 & 175 & 0 & $39 \%$ & $6 \%$ & $29 \%$ & $16 \%$ & $121 \%$ & $0 \%$ \\
\hline $\begin{array}{l}\text { Damage caused } \\
\text { while exercising } \\
\text { public powers }\end{array}$ & 542 & 171 & 9 & 84 & 48 & 179 & 34 & $32 \%$ & $5 \%$ & $49 \%$ & $28 \%$ & $105 \%$ & $20 \%$ \\
\hline $\begin{array}{l}\text { Repayment of } \\
\text { loan }\end{array}$ & 840 & 187 & 19 & 81 & 56 & 178 & 7 & $22 \%$ & $10 \%$ & $43 \%$ & $30 \%$ & $95 \%$ & $4 \%$ \\
\hline Total & 14,512 & 5,739 & 596 & 6,120 & 1,165 & 4,643 & 2,774 & $40 \%$ & $10 \%$ & $107 \%$ & $20 \%$ & $81 \%$ & $48 \%$ \\
\hline
\end{tabular}


3.3.6. Conclusions from the quantitative research

Above, at III.3., I showed that the court level and department have an impact on the use of precedents (upper courts and private law branches cite more frequently than any others). Table 11 provides further information on this.

The first visible phenomenon is that though the civil branch shows a higher citation rate, the distribution is extreme: there are some case types where the citation ratio is $90 \%$, while there are some where it is around $20 \%$. (The dispersion rate in the public law branches is not so high, since the highest and the lowest rates in administrative courts are $40 \%$ and $14 \%$, respectively, and in the penal law branches, these figures are $37 \%$ and $19 \%$, respectively.)

This means that there are case types where practically every decision is citing a precedent.

It is even more interesting to observe this together with the precedent types that the courts are citing. Since there is an obligatory document (the Uniformity Decision), which is officially more important than other types, one would think that this is the most frequent citation type, but that is not the case. In certain case types, there are no citations at all to UDs. This could be for a number of reasons.

One is that the number of UDs is low and the "corpus" is casuistic: UD's don't exist in certain areas of law at all.

Another reason becomes visible if we observe Constitutional Court decisions (CC column 8), in which there are extreme citation rates both in the positive and in the negative ranges. Here the cause is visible: all the case types in which constitutional court decisions are popular have some (or a great) connection with the basic rights - e.g., libel cases $(73 \%)$ and infringement of personal rights $(122 \%)$ in the civil branch, broadcasting cases in the administrative branch (107\%) and defamation in the penal branch (138\%).

A third reason is that if a certain precedent type is extremely popular, then the citation ratio of other types drops. It seems that the precedent types are interchangeable. This is a surprising fact, since these types are legally, and in their form, very different. As I indicated above, it is obligatory for courts to conform to Uniformity Decisions (UDs). This is not the case with Chamber Opinions (COs), but these are longer in text, and they comprise a broader legal topic (such as a legal act). Court Decisions (CDs) are, in format, very similar to Principal Decisions, and Uniformity Decisions, but their number is very high (as they decide one particular, narrow legal dilemma). But this all seems unimportant for everyday practice. The authority of a decision is independent from its intended "legal force" or from its place in the hierarchy of decisions. However, it seems that if there is a Chamber Opinion, courts prefer this: this is the situation in joint property cases $(191 \%)$, libel cases $(295 \%)$, personal rights infringement cases (95\%) - these are all fields, where there is a "strong" Chamber Opinion. Where there is no CO, the practice uses CD and PD in the second place. Constitutional Court decisions are cited independently from the Supreme Court acts, and in that field we do not see this correlation.

In Chapter IV, I will analyze the context of the citations, and other qualitative features, but it is important to note that Chamber Opinions are the kind of documents that are closer in format and wording to the structure and logic of a traditional code. They are really lawlike tools.

However this is only a numeric starting point, and does nothing to answer our initial question, which is whether citations raise the quality of reasoning. As with all statistical figures, these should be interpreted together with the results of qualitative research. 


\section{THE QUALITATIVE RESEARCH}

\subsection{Methodology}

Though the number, structure and dispersion of the citations to precedents already can tell a lot about the use of precedents, the precedential character of a legal system cannot be analyzed only by automatic, statistical tools. Therefore, I selected a random sample from the decisions of the Capital Appellate Court (Appellate level) and the Supreme Court (Curia).

The sample contains 520 upper court cases (with the preceding case), which were broken down as follows:

Table 9. Cases observed in the qualitative research

\begin{tabular}{|l|c|c|c|}
\hline Year of case & Capital Appellate Court & Curia & Total \\
\hline 2007 & 19 & 29 & 48 \\
\hline 2008 & 36 & 61 & 97 \\
\hline 2009 & 34 & 81 & 115 \\
\hline 2010 & 38 & 49 & 87 \\
\hline 2011 & 38 & 78 & 57 \\
\hline 2012 & 32 & 25 & 520 \\
\hline Total & 197 & 323 & \\
\hline
\end{tabular}

We then filled out an Excel spreadsheet, with the following data:

1. The subject of the decision

2. Citations

3. History of the case (affirmed, dismissed, modified)

4. The value of the case (if applicable)

5. Treatment of the cited precedent (followed, distinguished, overruled)

6. Treatment of citations of the lower court decision in appellate decision (ignore them, use them, or cite a new one.)

7. Who cited first the decision? (court or parties, if available)

The first two points are the same that were observed also in the quantitative research, and we only wanted to check the statistical data with manual tools. All other parameters can be explored only after reading the text of the judgments.

\subsection{Some remarks on the style of the decisions (demonstration, inference, justification, reasoning)}

One of the conclusions of the qualitative survey was that, in most of the cases, the precedents are cited very formally and mechanically. Sometimes even the text of the headnote is missing and only the number of the case is cited ("The court took the CD No. .... into consideration"), but in most of the cases courts are only citing the headnote of the cases as if these were texts of a statute. We have no exact data on this, but my estimation is that the great majority of the citations (more than 90\%) either contain a headnote as a quotation, or parts of (sentences from) the headnote without an explicit quotation, and less than $10 \%$ of the citations quote anything from the reasoning. As we will see later even if the case is distinguished, it is done with a stereotypical introductory formula ("The court has 
not taken the Court Decision No. ... into consideration, because its facts are different from the recent case"). If the court analyses the reasoning, its reasoning is no longer than one paragraph, but rather typically a sentence.

Moreover courts do not do two things. First, they do not see and use the precedents as a network of arguments. I have seen only one case (out of the 520) where a whole chain of arguments was developed in a case-law-like way. This case was one applying EU law, and analyzed the jurisdiction of the General Court of the EU. Furthermore, courts do not reformulate the ratio decidendi of the case in order to adapt it to the case in hand, as, for example, English courts often do. The justification of an average Hungarian decision seems like a logical operation, where the judgment (conclusion) is shown as a logical consequence of the facts, and the text of law.

\subsection{Results of the qualitative research}

4.3.1. Value of the case

\section{Table 10. The value of the case, and the citations}

\begin{tabular}{|l|c|c|c|}
\hline Value & All judgements & Number of citations & $\%$ \\
\hline Small (under 1M HUF) & 220 & 55 & 25 \\
\hline Medium (between 1 and 10 M HUF) & 126 & 36 & 29 \\
\hline Big (more than 10M HUF) & 71 & 22 & 31 \\
\hline Undetermined $^{29}$ & 103 & 184 & 179 \\
\hline Total & 520 & 297 & 57 \\
\hline
\end{tabular}

One of our hypotheses was that the value of the case - the money at stake - has an effect on the reasoning effort employed by the parties and that this influences the number of citations. This is not justifiable. Though the number of citations increases slightly as the value grows, this is not the decisive factor: the frequency of citations is determined mostly by the field of law or the case type in question.

\subsubsection{Distinguishing}

\section{Table 11. Number of precedents distinguished}

\begin{tabular}{|l|c|}
\hline Number of decisions & 520 \\
\hline Contains citation & 157 \\
\hline Number of all citations & 297 \\
\hline Precedent followed & 283 \\
\hline Precedent distinguished & 14 \\
\hline
\end{tabular}

It is not surprising, and it partly follows from the above mentioned facts, that $95 \%$ of precedents are cited in an affirmative, i.e. positive, context. If the court is distinguishing the

${ }_{29}$ Most of the "undetermined value" cases are: criminal, administrative (where the subject of the case is the supervision of a decision of a state organ), or labor (where e.g. the illicit termination of the labor contract is in question), or infringement of personal rights. The latter two are very precedentintensive - that is why the undetermined group has the highest citation ratio. 
case, it does so in a very mechanical way, mostly using the same stereotypical phrases, like "the facts in case XXX are different; therefore, the holding should not be applied in this case". We have not found any cases where there was an explicit overruling.

4.3.3. Treatment of citations by the lower court

Table 12. Treatment of citations of the lower courts in the context of the history of the case

\begin{tabular}{|l|c|}
\hline Number of decisions & 520 \\
\hline Contains citation & 157 \\
\hline Number of all citations by the upper court & 297 \\
\hline Number of all citations by the lower court & 104 \\
\hline Citations mentioned in a positive context by the upper court & 51 \\
\hline "Agreement ratio" in precedents & $49 \%$ \\
\hline Number affirmed cases & 377 \\
\hline Affirmation ratio & $73 \%$ \\
\hline
\end{tabular}

As was previously stated, lower courts cite fewer precedents than upper courts. In our sample, we found 297 citations in 520 judgments vs. 104 citations by the lower courts. The surprising result of the table is that typically the upper courts do not cite the same precedents as lower courts. Of the 297 citations made by the upper courts, only 51 were also used/cited by the lower courts. Or, to put it another way, only half of the citations used/made by the lower courts are also cited by the upper courts at appeal; another 246 totally different citations are inserted in the second (third) instance. Thus, typically the story is that if the lower court uses two citations, one is ignored, the second retained, and another two are newly inserted. This number is even more surprising if we compare it with the affirmation ratio of the upper courts, which is $73 \%$ overall.

4.3.4. By whom is the precedent cited and brought into the argumentation?

Table 13. By whom the precedent was brought into the reasoning

\begin{tabular}{|l|r|r|}
\hline At lower courts & & \\
\hline By the court & 83 & $80 \%$ \\
\hline By the parties & 21 & $20 \%$ \\
\hline Total & & 104 \\
\hline At upper courts & 51 & $17 \%$ \\
\hline By the lower court, and the upper court agrees & 190 & $64 \%$ \\
\hline By the upper court & 56 & $19 \%$ \\
\hline Parties & 297 & $100 \%$ \\
\hline Total & & \\
\hline
\end{tabular}

An important question for us was who had introduced the citation into the procedure. Who initiated the use of a precedent? Unfortunately, we did not find a clear answer to this. In most of the cases there is no sign of the source. In other cases the court indicates that this was proposed by the party ("Defendant cited the CD No .....,") or was used by the lower 
court ("The first instance court cited properly CD No...."). For this particular question, to get a better picture, the text of the petitions should have been studied too.

\subsection{Final conclusions}

Precedents seem to be an important part of the legal reasoning of the Hungarian courts, and the number of citations of precedents is significantly increasing over time (from $27 \%$ to $40 \%$, between 2007 and 2012; on average $33 \%$ ). ${ }^{30}$ If trends continue, within a few years more than half of all decisions will contain a precedent citation.

However, this data in itself is slightly misleading. If we analyze this fact in light of the other results and observations, it will become clear that the way in which Hungarian courts are citing previous decisions is simply not increasing the quality of reasoning. Citations have no direct effect on the quality of reasoning.

First, courts, even if they cite precedents, do so in a formal way. This means the following: courts almost exclusively cite the official headnotes of the decisions, and it is very rare that they cite anything else. Therefore they do not analyze the previous case, do not try to build up a reasoning upon it, but simply mention it as a premissa maior of a logical subsumption. This is very similar to the use of the law texts in some continental legal cultures. In Hungary judicial reasoning - reflecting the long-standing tradition of civil law systems - is not a rhetorical effort, but shows itself as a logical process.

Second, there is neither distinguishing, nor any other sophisticated approach to a case used, as we can see in section IV.3.2. Rather, the approach of courts to cases is binary. If the case cited by the party does not fit the "inference" of the court, the court simply ignores it, and will not waste time explaining why. If it fits, the court will cite it like an amendment of a law. The overwhelming popularity of Chamber Decisions, which regulate a particular field of law, and their statute-like wording illustrates this tendency.

Third, the number of citations is mainly determined by the field of law, and neither the value of the case, nor the complexity of the legal issue has any significance. In other words, judges are not using previous cases when they are struggling with a complicated legal issue, rather they simply mechanically follow certain patterns.

Fourth, citations to previous cases demonstrate that the judgment fits into a professional "seamless web". Quality means different things for different target groups and audiences. For example, for the general public moral arguments are more important than demonstrating professional quality. Citations to previous cases could be important for the legal community, or for the parties' counsels. There are strong arguments ${ }^{31}$ that judges in their decisions in Hungarian courts are mainly speaking to the upper court, and not to the legal community.

\section{LITERATURE}

Austin, J. M., 'The Law of Citations and Seriatim Opinions: Were the Ancient Romans and the Early Supreme Court on the Right Track?' (2010) 31 Northern Illinois University Law Review 19-36.

Bast, C. M., 'What's in a Name? Shepard's Citators' (1998) 14 Journal of Paralegal Education and Practice 41-58.

Beniger, J. R., The Control Revolution (Harvard University Press 1986)

30 See 2.2.2.

31 See 3.3.3. 
Cross, F. B., Spriggs II,J. F., Timothy, R. J. and Wahlbeck, P. J., 'Citations in the U.S Supreme Court: An Empirical Study of their Use, and Significance 2010' (2010) University of Illinois Law Review 489-576.

Friedman, L. M., Kagan, R. A., Cartwright, B. and Wheeler, S., 'State Supreme Courts: A Century of Style and Citation' (1981) 33 Stanford Law Review 773-818.

Garfield, E., 'Citation Indexes to Science: A New Dimension in Documentation through Association of Ideas' (1955) 122 Science 108-111.

Goutal, J. L., 'Characteristics of Judicial Style in France, Britain and the U.S.A.' (1976) 24 American Journal of Comparative Law (1976) 43-72.

Johnson, C. A., 'Citations to Authority in Supreme Court Opinions' (1985) 7 Law \& Policy 509-523.

Landes, W. A. and Posner, R. A., 'Legal Precendent: A Theoretical and Empirical Analysis' (1976) 19 Journal of Law\&Economy 249-308.

McCormick, P., 'Judicial Citation, the Supreme Court of Canada and the Lower Courts: The Case of Alberta' (1996) 34 Alberta Law Review 870-891.

Merryman, J. H., 'The Authority of Authority: What the California Supreme Court Cited in 1950' (1953-1954) 6 Stanford Law Review 613-673.

Merryman, J. H., 'Toward a Theory of Citations: An Emprical Study of the Citation Practice of the California Supreme Court in 1950, 1960, and 1970.' (1977-1978) 50 Southern California Law Review 381-396.

Smyth R., 'An Empirical Study of Citation Practice in the New Zeeland Court of Appeal' (2000) 31 Victoria University Wellington Law Review 847-895.

Wagner-Döbler, R. and Lothar, P., 'Präjudizien in der Rechtsprechung: Statistische Untersuchungenanhand der Zitierpraxisdeutscher Gerichte' (1992) 23 Rechtsteorie 228-242.

Watson, A., Law out of Context (University of Georgia Press 2000)

West, J. B. 'The Multiplicity of Reports' (1909-1910) 2 Law Library Journal 15-45. 